Volume 15 - Número 1 - jan/jul de 2020

\title{
MANUEL BANDEIRA E O PORTUGUÊS DO BRASIL
}

\section{MANUEL BANDEIRA AND BRAZILIAN PORTUGUESE}

\author{
André Cervinskis ${ }^{1}$
}

\begin{abstract}
RESUMO: Este artigo procura discutir a opinião de Manuel Bandeira sobre o idioma nacional (português do Brasil), centrado em questões de nacionalidade e identidade através de expressões linguísticas e literárias, tanto em seus versos quanto em suas crônicas. Desde os inícios do Modernismo, Bandeira posicionou-se a favor de um português do Brasil, uma variante do português, mas que conservou características da miscigenação, empreendida aqui pelo colonizador, defendendo que a fala do povo deveria ter lugar nos romances nacionais, como o fazia Mário de Andrade. A procura dessa brasilidade perpassa toda obra poética de Bandeira, desde a valorização da cultura popular, do jeito de ser do brasileiro, até a defesa de um português do Brasil. E essa singularidade, na maneira de escrever e falar do brasileiro, foi assumida categoricamente por Manuel Bandeira, depois de impulsionada por Mário de Andrade, especialmente por meio das inúmeras crônicas que escreveu e da correspondência mantida com ele, por mais de 20 anos. Na sua poesia, encontramos traços de brasilidade, como a religiosidade dessacralizada (trato informal e afetivo com os santos); valorização da oralidade e da cultura popular (a voz do povo recheada de falares e gírias), manifestando a influência cultural das três identidades que formam a brasileira (a europeia, a indígena e a africana). E essa mesma voz apareceria de forma implícita ou velada, mas sempre com propriedade, sem maiores censuras, em muito de sua produção em prosa também, com suas crônicas semanais no jornal $A$ província, de Recife, e nos periódicos do Rio de Janeiro, especialmente o Jornal do Brasil, entre as décadas de 20 e 30.
\end{abstract}

PALAVRAS-CHAVE: Manuel Bandeira e o português do Brasil; Manuel Bandeira; idioma nacional

ABSTRACT: The following article discuss Manuel Bandeira's opinion on the national idiom (Brazilian Portuguese), centered around matters of nationality and identity presents within linguistic and literally expressions, both in his verses and chronicles. Ever since the early days of Modernism, Bandeira had put himself in favor of a Brazilian Portuguese, a variant of the language that inherits aspects of cultural exchanges, brought forth by the colonizers, defending that the way the common people talk should have a proper place within national literature, like Mário de Andrade had done before him. That peculiarity in Brazilian's writing and speaking style was categorically inherit by Manuel Bandeira just after Mário de Andrade gave it its initial push, especially seen on the countless chronicles he wrote and all the letters he kept for more than 20 years. The search for a specific Brazilian style can be seen throughout all Bandeira's poetry, from giving popular culture the value it deserves, the meaning behind being Brazilian, to defending a proper Brazilian Portuguese. In his poetry, we find traces of this Brazilian style, like the desecration of religion (informal and affective way of portraying the divine); appreciation for orality and popular culture (people's voice filled with slangs), manifesting all three major ethnical influences presents in Brazilian culture (European, African and Indigenous). That same voice would show, in a way, implicit and sealed, but always objective, without major censorship, also in most of his work with proses, like the weekly chronicles he wrote for the A provincia newspaper, in Recife, and also for newspapers from Rio de Janeiro, specially Jornal do Brasil, between the decades of 1920 and 1930.

KEYWORDS: Manuel Bandeira and Brazilian Portuguese; Manuel Bandeira; national language

1 Doutorando em Literatura e Interculturalidade pela Universidade Estadual da Paraíba (UEPB). E-mail: acervinskis@gmail.com. Pesquisador-bolsista da FAPESQ. 
Volume 15 - Número 1 - jan/jul de 2020

\title{
1 Introdução
}

Tendo nascido em 1886, Manuel Bandeira passa os primeiros anos de sua infância convivendo com pessoas desprovidas de letramento, possuindo como única forma de preservação de sua memória a transmissão de canções, ditos populares e mitos para as gerações futuras. No poema "Vou-me embora pra Pasárgada", tem como um de seus desejos idílicos do país Pasárgada mandar chamar "a mãe-d'água/ Pra me contar as histórias/ que no tempo de eu menino/ Rosa vinha me contar." (BANDEIRA, 1993, p. 143)

Analisando tais aspectos linguísticos na obra bandeiriana, isto é, no dizer de Candido (1964) e Santiago (1995), a "cor local”. Em relação ao idioma pátrio, em seu capítulo "Um diálogo de 22 anos", Espinhara Filho (2004) destaca a descoberta e revelação do Brasil, discorrendo sobre a discussão da língua nacional em Bandeira. Nesse assunto, assim nos introduz:

\begin{abstract}
Um dos assuntos mais frequentes era o abrasileiramento da linguagem. $\mathrm{O}$ que era compreensível, pois o país vinha de uma sujeição quase absoluta ao lusitanismo, ao menos em literatura, e uma das propostas do modernismo - sobretudo de Mário de Andrade - era exatamente escrever brasileiramente. A discussão não se limitava ao nível das palavras ou das expressões, levando em consideração a sensibilidade própria da gente brasileira e suas variadas regiões. Variedade que desaguava num todo chamado Brasil, nação que os modernistas estavam tentando descobrir e revelar ao mundo. Esta atenção às manifestações culturais do povo era um dever do intelectual (ESPINHARA FILHO, 2004, p. 171)
\end{abstract}

Discorrendo sobre se há ou não uma língua brasileira, Eni Orlandi (2005) considera que, não obstante a opressão colonialista, sobretudo linguística, a fala do brasileiro (ela afirma que há uma fala diferente, embora dentro da mesma língua portuguesa) sobrepôs-se ao modo de dizer do colonizador, à sua discursividade, graças à assimilação de outras culturas, notadamente a africana e a indígena:

Desde o princípio da colonização, instala-se um acontecimento linguístico de grande importância no Brasil: o que constitui a língua brasileira. Ao mesmo tempo em que aqui desembarca, a língua portuguesa, ao deslocar-se de Portugal para o país nascente - o Brasil, institui um movimento de memória, deslizamentos linguísticos por meio dos quais outra língua - a brasileira - faz-se presente. O novo espaço de comunicação resiste com sua materialidade à língua que chega com os portugueses em sua memória já falada, já dita. Desdobram-se, transmudam-se os modos de dizer. A relação palavra-coisa faz ruído, relação não coincidente entre si e nem perfeitamente ajustada. Outras formas vão estabelecer-se fazendo intervir, e ao mesmo tempo, constituindo a memória local. (...) A língua praticada nesse outro regime enunciativo realiza, deste lado do Atlântico, a relação unidade/variedade: a unidade já não se refere ao português do Brasil ou ao de Portugal, mas à unidade e às variedades existentes no Brasil. (...) A variação não tem como referência Portugal, mas a diversidade concreta produzida no Brasil, na convivência de povos de línguas diferentes (línguas indígenas, africanas, de imigração etc.). Nessa perspectiva, então, falamos decididamente a língua brasileira, pois é isto que atesta a materialidade linguístico-histórica. Se, empiricamente, podemos dizer que as diferenças são algumas, de sotaque, de contornos sintáticos, de uma lista lexical, no entanto, do ponto de vista discursivo, no modo como a língua se historiciza, as diferenças são incomensuráveis: falamos diferente, produzimos diferentes discursividades (ORLANDI, 2005, p. 24 - grifos nossos) 
Concordando com Orlandi, Bandeira defende que haja uma língua brasileira, a língua portuguesa como literária e artística, como nos relata em prefácio às Cartas a Manuel Bandeira, de Mário de Andrade:

\begin{abstract}
Outra coisa que vemos largamente nesta correspondência é o caso da língua. Sempre fui partidário do abrasileiramento do nosso português literário, de sorte que aceitava em princípio a iniciativa de Mário. Mas discordava dele profundamente na sua sistematização, que me parecia indiscretamente pessoal, resultando numa construção cerebrina, que não era língua de ninguém. Eu não podia compreender como alguém, cujo fito principal era "funcionar socialmente dentro de uma nacionalidade", se deixava levar, por espírito de sistema, a escrever numa linguagem artificialíssima, que repugnava a quase totalidade de seus patrícios. Mário, que se prezava de psicólogo, escrevia-me, para justificar-se de seus exageros, que era preciso forçar a nota: "exigir muito dos homens pra que eles cedam um poucadinho". O reformador não se limitava a aproveitar-se do tesouro das dicções populares, algumas tão saborosas como esse "poucadinho", nascido por contaminação de "pouco" e "bocado". Ia abusivamente além procedendo por "dedução lógica, filosófica e psicológica" (ANDRADE \& BANDEIRA, 1966, p. 33 - grifos nossos)
\end{abstract}

De fato, desde os inícios do Modernismo, Bandeira posicionou-se a favor de um português do Brasil; uma variante do português, mas que conservou características da miscigenação empreendida aqui pelo colonizador, defendendo que a fala do povo deveria ter lugar nos romances nacionais, como o fazia Mário de Andrade, na opinião de Bandeira, expressa na crônica Amar, verbo intransitivo, em que discorre sobre o livro andradino de mesmo nome, em comparação com Dédalo, de Joyce:

\footnotetext{
Não que tenha entre as duas nenhum ponto de contato, senão este: ambas são profundamente nacionais - brasileira, gostosissimamente brasileira a de Mário; irlandesa a do outro; todas duas, porém, resolvendo no leitor a mais reflexiva, a mais comovida humanidade e, portanto, obras universais. [...] a língua! É preciso prevenir o público destes nortes da tentativa nobilíssima de Mário. A linguagem do romance está toda errada. Errada no sentido portuga da gramática que aprendemos em meninos do ponto de vista brasileiro, porém, ela é que está certa, a de todos os outros livros é que está errada. Mário se impõe à sistematização dos nossos modismos. [...] Viva o falar gostoso, arrastado e molenga desses carões morenos do Brasil! Podem nos desprezar à vontade: sabemos falar também: "Quintilhas de Frei Antão". É só pedir por boca. Não insistirei sobre isso. Quis só avisar (BANDEIRA, 2008, p. 110 - grifos nossos)
}

\title{
2 "Abrasileirando" o português
}

Percorrendo sua obra, percebemos que o poema Evocação do Recife é uma louvação ao modo de falar do brasileiro, do povo simples, que, sem "macaquear a sintaxe lusíada", fala gostoso o português do Brasil, incorporando a musicalidade do negro e do indígena, as palavras de origem africana e indígena, que transforma o português falado em nosso país numa forte característica identitária: "Língua errada do povo/ Língua certa do povo/ Porque ele é que fala gostoso o português do Brasil/ Ao passo que nós/ O que fazemos/ É macaquear/ A sintaxe lusíada" (BANDEIRA, 1993, p. 133 - grifos nossos)

Note-se que Bandeira referiu-se ao português do Brasil; isso demonstra uma tomada de posição do poeta. Ele defendia uma fala brasileira, mas afirmava ser o português o que realmente nos caracteriza linguisticamente. Pois, conforme afirmou no artigo "Fala Brasileira" (Crônicas da província do Brasil, 2006): 
Volume 15 - Número 1 - jan/jul de 2020

Um lingüista como ele (Nascentes) o é, não podia absolutamente usar naquela denominação (idioma nacional) para encobrir a realidade das coisas, nem entrar na corrente delirante dos que pretendem, pela simples resolução de adotar na língua escrita todas as licenças da língua falada, criar uma língua nova, uma língua que querem não seja portuguesa, sem se lembrarem de que, com esse processo, apenas conseguiriam (se veleidades humanas pudessem desviar o curso natural das coisas) escrever uma língua que seria a portuguesa com alterações numerosas e talvez profundas, mas sempre e em substância a língua portuguesa (BANDEIRA, 2006, p. 45)

Envolvido em tal discussão com Sousa da Silveira, Bandeira que, embora admitindo, nos outros, certas liberdades, continua defensor da tradição literária escrita. E equivoca-se em sua crítica, pois ninguém jamais falara em criar uma língua nova, uma "língua brasileira". Nem mesmo Mário de Andrade, o qual jamais se propusera publicar uma "gramatiquinha" da língua brasileira - e sim da fala do Brasil. O que ele queria, afirma Bandeira, era "criar na linguagem escrita uma tradição mais próxima da linguagem falada natural, correta sem afetação literária, da sociedade brasileira culta" (BANDEIRA, 2006, p. 47). Assim, refletindo sobre a relação fala-escrita brasileira, sentencia o poeta:

Entre esta linguagem e a tradição literária existe um abismo como não há em país algum, inclusive o próprio Portugal. É que a linguagem literária entre nós se divorciou da vida. Falamos com singeleza e escrevemos com afetação (BANDEIRA, 2006, p. 47 - grifos nossos)

Lembra Bandeira, em tal artigo, as acusações de desleixo que sofreu Lima Barreto, como também os ataques dos gramáticos a José de Alencar, no seu tempo. Continuando, Bandeira aborda a luta de Mário de Andrade, que, em sua obra, empreende "a adoção integral da boa fala brasileira" (BANDEIRA, 2006, p. 46).

A procura dessa brasilidade na escrita e na fala brasileiras foi assumida por Manuel Bandeira depois de impulsionada por Mário de Andrade. Defendendo mistura de realidades, sem purismos nem regionalismos, Bandeira sintetiza o propósito do amigo modernista: "Abrasileirar o brasileiro num sentido total, patrializar a pátria ainda tão despatriada, quer dizer, concorrer para a unificação psicológica do Brasil" (BANDEIRA apud ESPINHARA FILHO, 2004, p. 172). Noutro texto (“O Idioma Nacional”, Revista do Brasil, 15 de novembro de 1925), comentando sobre o trabalho linguístico de Antenor Nascentes acerca do linguajar carioca, usando a próclise no lugar da ênclise, exprimiria:

O senhor Antenor Nascentes declara em prefácio querer respeitar as legítimas tendências da língua portuguesa no Brasil, por entender "que todas as modalidades fonéticas, semânticas e sintáticas, correntes no Brasil e corretas, devem ser preferidas, pois representam o genuíno modo de falar do nosso povo'. Nos alegramos de ver tais palavras em boca de tal prestígio linguístico (BANDEIRA, 2008, p. 108 - grifos nossos)

E, em outra crônica, escrita, em 12 de maio de 1929, para A Província ("Alencar e a linguagem brasileira"), a respeito da linguagem mais solta defendida por José de Alencar em seus romances, por ocasião do centenário do escritor, Bandeira afirmaria o seguinte:

Não foi ele apenas o primeiro a querer escrever nos seus romances o português dos brasileiros. Mas, fazendo-o, deu-nos também o verdadeiro senso da adaptação artística da nossa linguagem. Podia ter ido bem mais longe. Nunca, porém, errou por 
Volume 15 - Número 1 - jan/jul de 2020

excesso de medida ou intenção. É preciso frisar bem esse ponto, porque ultimamente tem havido novas e mais arriscadas tentativas de aproveitamento literário das formas brasileiras, ensaios que apesar de muito louváveis pela coragem e pelo sabor de muitas páginas, todavia vão ficando prejudicados pelos excessos de uma sistematização que acaba destruindo toda a naturalidade da dicção. O Macunaíma, livro, aliás, delicioso, é de leitura tão difícil quanto as Páginas de estética, também deliciosas. Num e noutro há purismo. E o purismo, de qualquer sorte que seja, sempre é coisa monstruosa e para evitar. Vamos ser brasileiros - mas com discrição. Como foi Alencar (BANDEIRA, 2008, p. 198 grifos nossos)

Noutra crônica (Vocabulário gaúcho, Revista do Brasil, 31 de janeiro de 1927), comentando acerca do livro de mesmo nome, de autoria de Roque Callage (Porto Alegre: 1927), que estudou o linguajar característico do Rio Grande do Sul, Bandeira apresentou seu respeito pelos falares regionais, em detrimento desse excessivo purismo, comentado anteriormente:

Valiosíssima contribuição para a nossa dialetologia. Mais de 2 mil termos usados no linguajar rio-grandense, com a vantagem de muitas vezes se esclarecer o sentido das palavras com citas de literatura regionalista. Se em todos os estados algum estudioso procedesse à mesma tarefa, teríamos em breve a possibilidade de organizar a síntese do léxico brasileirista, onde há tanta riqueza de expressão. Saber-se-ia o que é propriamente regional, e depois, uma vez registrados todos esses regionalismos, a literatura se encarregaria de nos desregionalizar, estendendo-os a todo o país (Idem, p. 109 - grifos nossos)

\section{Oralidade e cultura popular}

Para não ficar somente na retórica, Bandeira chegou a usar a tendência brasileira de colocar pronomes no início das frases, valorizando, assim, certas características da fala cotidiana, num texto em que se referia ao artesanato de Vitalino, repetindo atitude já esboçada:

Já tive algumas dessas figurinhas em minha casa. Não sei se era de Vitalino ou de Severino.[...] acabei dando o meu papagaio. Sempre acabei dando meus calungas de barro, mesmo porque, quando não se dá, elas se quebram. Se quebram com a maior facilidade (BANDEIRA, 1997, p. 142 - grifos nossos)

Como podemos perceber, através desse comentário, traços de oralidade são constantes na poesia do autor modernista. A tradição oral foi responsável pela preservação de muitos traços da memória brasileira, especialmente em relação à identidade da gente simples. Antes de transpor-se ao papel, na verdade, toda poesia passa por um processo oral; os versos nascem na memória, coordenam-se na inteligência do autor e desembocam no poema escrito. A voz seria, então, a forma arquetípica da linguagem; imagem primordial e criadora. A voz humana, novamente, uma oralização, uma encenação do fundo de nossas memórias. Memória como simbolismo primordial, quando voz e linguagem constituem valores de uma situação antropológica. Dessa forma, segundo Paul Zumthor:

Estas (tradições) menos por elas mesmas do que geradas na memória daqueles que as vivem e vivem delas. (...) A língua, liame da coletividade, propicia a única possibilidade de fazer conhecer o nome e a conduta dos ancestrais, assim como a razão de ser do grupo (comunidade) no dia-a-dia; mas a palavra oral, interiorização da história, não se desenrola no tempo como uma sequência de acontecimentos; ela 
Volume 15 - Número 1 - jan/jul de 2020

se sucede dialeticamente a si mesma, em constante reorientação de escolhas existenciais, alterando-se a cada vez que nela ressoa a totalidade de nosso ser no mundo. Vozes cotidianas da comunidade tecem nela e por ela uma trama contínua, horizontal, sucessiva, de onde surge e se distingue a dos poetas, uma, formando (numa dimensão temporal que lhe é própria) uma continuidade vertical (ZUMTHOR, 1997, 263.265)

De fato, essa valorização das manifestações e figuras populares e outras características de brasilidade apresentam-se já em seu primeiro livro (A Cinza das Horas, 1917), como podemos constatar através do poema $O$ Anel de Vidro, onde o poeta incorpora uma modinha popular à sua poesia:

\begin{abstract}
Aquele pequenino anel que tu me deste,/ - Ai de mim - era vidro e logo se quebrou.../ Assim também o eterno amor que prometeste,/ - Eterno! Era bem pouco e cedo se acabou./ Frágil penhor que foi do amor que me tiveste,/ símbolo frágil da afeição que o tempo aniquilou - / aquele pequenino anel que tu me deste,/ - ai de mim - era vidro e logo se quebrou... (BANDEIRA, 1993, p. 74 - grifos nossos)
\end{abstract}

Dessa forma, assumindo para si o papel de baluarte da poesia oral, como seu arauto, visita as canções da sua infância, por exemplo, que são recordadas em versos inteiros no Evocação do Recife, inclusive com um neologismo:

À distância as vozes macias das meninas politonavam: Roseira dá-me uma rosa/ Craveiro dá-me um botão/ (Dessas rosas muito rosa/ Terá morrido um botão...)" (idem, p. 134). Também as brincadeiras dos meninos: "A gente brincava no meio da rua/ Os meninos gritavam:/ coelho sai!/ Não sai!' (idem, p. 134) (BANDEIRA, 1993, p. 134 - grifos nossos)

\title{
4 Indígena e africano também
}

Nalguns poemas de Manuel Bandeira, a voz do povo é recheada de falares e gírias, descendentes diretos ou indiretos das três identidades que formam a brasileira (a européia, a indígena e a africana). E ela apareceria de forma implícita ou velada, mas sempre com propriedade, como neste poema em que Bandeira ressalta, através de nomes indígenas, a herança dos ameríndios em nossa cultura linguística:

\section{CUNHANTÃ}

Vinha do Pará/Chamava Siquê./ Quatro anos. Escurinha. O riso gutural da raça./ Piá branca nenhuma corria mais do que ela/ Tinha uma cicatriz no meio da testa:/ - Que foi isto, Siquê?/ Com voz de detrás da garganta, a boquinha tuíra:/ - Minha mãe (a madrasta) estava costurando/ Disse vai ver se tem fogo/ Eu soprei eu soprei eu soprei não vi o fogo/ Aí ele se levantou e esfregou com minha cabeça na brasa (BANDEIRA, 1993, p. 138)

Na observação atenta também de nossas raízes afro-brasileiras, Bandeira publica a crônica "Candomblé', relatando a visita de amigos a um terreiro. Essa atitude positiva em relação às práticas religiosas afro-brasileiras era difícil de ser encontrada, mesmo entre a primeira geração modernista de 1920:

O grupo, composto de quatro companheiros de bar - o pintor Cicinho de Batateira, o poeta sem fé, sem pão, sem lar, o modesto sociólogo e o Poliglota Antenor -, saiu em demanda do candomblé, que durava havia três dias, segundo informar o pinto 
Volume 15 - Número 1 - jan/jul de 2020

Cicinho. Era na rua das laranjeiras, e quem passasse por ali não suspeitaria jamais que houvesse na cidade um cortiço daquele feitio. [...] O grupo entrou, com a devida licença, na salinha do candomblé. Sentiu-se logo haver uma mistura de bodum de negro e sangue fresco de galinha. [...] Are you going eat it? Perguntou ao Poliglota o modesto sociólogo, o que traduzido em vulgar responde assim: "Seu mano, você vai comer essa porqueira?" Mas o receio do grupo era desnecessário: só tinham direito e dever de cumprir o rito os que estavam presentes desde o início da sessão. [...] Tinha acabado a sessão. Pai-de-santo disse: - Quem é de abença, abença; quem é de boanoite, boa noite (BANDEIRA, 2006, p. 175-177)

Assim, em Manuel Bandeira, a religiosidade negra é transubstanciada em poesia; inclusive com falas características do Terreiro de Candomblé, legítimo representante do sincretismo do Brasil, que uniu, numa só crença, elementos religiosos africanos e europeus, como demonstra nesse poema:

MACUMBA DO PAI ZUSÉ

Na macumba do Encantado/ Nego veio pai de santo faz mandinga/ No palacete de Botafogo/ Sangue de branca virou água/ Foram vê estava morta! (BANDEIRA, 1993, p. 141)

Semelhantemente, voltando-se para as tradições nordestinas, em crônica de Flauta de papel (1957), Bandeira reverencia a cultura popular, através da Feira de Caruaru, posta em contraste com as do Rio:

A feira semanal de Caruaru não é como estas do Rio não. É toda a rua do Comércio, quer dizer, um estirão de quilômetros, tão comprida quanto a mesma cidade, e onde se compra de um tudo, desde o gado em pé até o que você possa imaginar, salvo, bem entendido, geladeira elétrica e automóvel Cadillac (BANDEIRA, 1997, p. 140)

Falando sobre a arte de Vitalino, legítimo representante do artesanato brasileiro, o poeta reverencia a perfeição das peças e o retrato da vida cotidiana por elas revelada, não se opondo a algumas concessões em nome da modernidade, como o fez seu primo, Gilberto Freyre, atento ao caminho da complexidade de Vitalino:

Também a arte de Vitalino veio se complicando. Já não se limita ele aos simples bichinhos de plástica tão ingenuamente pura. Atira-se a composições de grupos, com meio metro de comprido e uns vinte centímetros de altura. Cenas da terra: casamentos, confissões na igreja, o soldado pegando ladrão de galinhas ou o bêbado, a moenda, a casa de farinha etc. Já vi Gilberto Freyre esbravejar contra essa degeneração para o anedótico numa arte que encantava tanto sem auxílio da anedota. Foi em casa de João Condé, que naturalmente não ousou piar na frente do trovejante mestre de Apipucos. Mas, cá para nós, ele bem que gosta do matuto no alto do pé de pau e atirando nas duas onças... (BANDEIRA, 1997, p. 141)

No sentido de destacar a cultura popular brasileira, afirmando sua nordestinidade e trazendo, para sua obra, a voz dos artistas de sua região, numa atitude de valorização da cultura popular, publica "Cantadores do Nordeste", seguindo o ritmo do repente:

Anteontem, minha gente,/Fui juiz numa função/ De vileiros do Nordeste/ Cantando em competição,/ Vi cantar Dimas Batista,/ Otacílio, seu irmão./ Ouvi um tal de Ferreira, Ouvi um tal de João./ Um, a quem faltava o braço,/ Tocava cuma só mão:/ 
Volume 15 - Número 1 - jan/jul de 2020

Mas, como ele mesmo disse,/ Cantando com perfeição,/ Para cantar afinado, /Para cantar com paixão./ A força não está no braço:/ Ela está no coração./(...) Como faz Dimas Batista/ E Otacílio, seu irmão;/ Bom cantador do sertão,/ A todos os quais, humilde,/ Mando a minha saudação! (BANDEIRA, 1993, p. 256)

Note-se que Bandeira, nesse poema, respeitou a métrica dos repentistas, como também a rima, procurando imprimir nele o mesmo ritmo que os cantadores imprimem à sua arte. Realiza, dessa maneira, um perfeito casamento entre a tradição da poesia (métrica) e a modernidade (trazendo a expressão popular para dentro do lirismo). Perfeitamente enquadrado ao movimento modernista, portanto, embora preservando sua fidelidade a essa "língua certa" do povo. Nesses versos, também podemos perceber o primor com que Bandeira elaborava o ritmo de seus versos; na verdade, a musicalidade, para o poeta, importava tanto ou mais que a métrica, como nos revela em depoimento no seu Itinerário de Pasárgada:

Cedo compreendi que o bom fraseado não é o fraseado redondo, mas aquele em que cada palavra está no seu lugar exato e cada palavra tem uma função precisa, de caráter intelectivo ou puramente musical, e não serve senão a palavra cujos fonemas fazem vibrar cada parcela da frase com ressonâncias anteriores e posteriores. Não sei se estou sutilizando demais, mas é tão difícil explicar por que um desenho ou num verso esta linha é viva, aquela é morta. (BANDEIRA, 1997, p. 313)

Nesse poema, Bandeira subverte a norma culta em detrimento dos regionalismos: utiliza o verbo "botar" como é empregado até hoje no Nordeste, no sentido de "colocar'. Pois, como revela-nos o próprio autor, em depoimento: "Aproveito a ocasião para jurar que jamais fiz um poema ou verso ininteligível para me fingir de profundo sob a especiosa capa do hermetismo. Só não fui claro quando não pude - fosse por deficiência ou impropriedade de linguagem, fosse por discrição”. (BANDEIRA, 1997, p. 313).

Exemplo desse cuidado com musicalidade, herdado dos românticos, está em "Debussy", em que o poeta tematiza o movimento de um novelozinho de lã, encontrando ritmo de poesia num gesto do quotidiano:

Para cá, para lá.../ Para cá, para lá.../ Um novelozinho de linha.../ Para cá, para lá.../ Para cá, para lá.../ Oscila pela mão de uma criança/ (vem e vai...)/ Que delicadamente e quase a adormecer o balança/ - Psiu... - / .../ Para cá, para lá.../ Para cá e.../ - O novelozinho caiu (BANDEIRA, 1993, p. 90)

Noutras duas crônicas, ambientado à cultura carioca, o poeta reverencia Sinhô, conhecido sambista do Rio, nos anos 20 e 30 do século passado, e, nele, a sabedoria e encantamento da cultura popular ("O enterro de Sinhô', Crônicas da província do Brasil):

O que há de mais povo e mais carioca tinha em Sinhô a sua personificação mais típica, mais genuína e mais profunda. De quando em quando, no meio de uma porção de toadas que todas eram camaradas e frescas, como as manhãs dos nossos suburbiozinhos humildes, vinha de Sinhô, um samba definitivo, um "Claudionor", um "Jura", com um "beijo puro na catedral do amor", enfim uma dessas coisas incríveis que pareciam descer dos morros lendários da cidade, Favela, Salgueiro, mangueira, São Carlos, fina flor extrema da malandragem carioca mais inteligente e mais heroica.. Sinhô! Ele era o traço mais específico ligando os poetas, os artistas, a sociedade fina e culta às camadas profundas da ralé urbana. Daí a fascinação que despertava em toda a gente quando levado a um salão (BANDEIRA, 2006, p. 98) 
Procurando pela autoria de um samba supostamente composto por Sinhô, Bandeira percebe que a memória é condição essencial para a preservação da cultura (por isso, muitas tradições são anônimas) e consagra a mistura de raças e naturalidades como raiz do samba, autêntico ritmo brasileiro ("Sambistas"):

\begin{abstract}
Isso tudo me fez refletir como é difícil apurar a final de contas a autoria desses sambas cariocas que brotam não se sabe donde. Muitas vezes a gente está certo que vem de um Sinhô, que é majestade, mas a verdade é que o autor é seu Candu, que ninguém conhece. E afinal quem sabe lá se é mesmo de seu Candu? Possivelmente atrás de seu Candu estará o que não deixou vestígio de nome no samba que toda a cidade vai cantar. E o mais acertado é dizer que quem fez esses choros tão gostosos não é A nem B, nem Sinhô nem Donga: é o carioca, isto é, um sujeito nascido no Espírito Santo ou em Belém do Pará (BANDEIRA, 2006, p. 155)
\end{abstract}

Para Bandeira, há sonoridade na fala do povo; por isso, ele respeita as duas formas de nominar o rio principal que corta Recife: Capiberibe! - Capibaribe. Sobre tal referência, segreda-nos o poeta em seu testamento literário:

\begin{abstract}
$\mathrm{Na}$ "Evocação do Recife", as duas formas "Capibaribe - Capiberibe" têm dois motivos. O primeiro foi um episódio que se passou comigo na classe de geografia do Colégio Pedro II. Era nosso professor o próprio diretor do Colégio - José Veríssimo. Ótimo professor, diga-se de passagem, pois sempre nos ensinava em cima dos mapas e de vara em punho. Certo dia perguntou à classe: "Qual o maior rio de Pernambuco?" Não quis que ninguém se me antecipasse na resposta e gritei imediatamente: "Capibaribe" Capibaribe com $a$, como sempre tinha ouvido dizer no Recife. Fiquei perplexo quando Veríssimo comentou, para grande divertimento da turma: "Bem se vê que o senhor é pernambucano!" (pronunciou "pernambucano" abrindo bem o $e$ ) e corrigiu: "Capiberibe'. Meti a viola no saco, mas na "Evocação" me desforrei do professor, intenção que ficaria para sempre desconhecida se não a revelasse aqui. Intenção musical: Capiberibe a primeira vez com e, a segunda com a, me dava a impressão de um acidente, como se a palavra fosse uma frase melódica dita da segunda vez com bemol na terceira nota (BANDEIRA, 1997, p. 314)
\end{abstract}

Atitude afirmativa essa de Bandeira, colocando pari passu o erudito e o popular, levando a sonoridade da fala brasileira para sua poesia. Semelhante ambiente permanece na memória afetiva do poeta, fazendo com que ele não aceite quaisquer sinais de modernidade na sua cidade natal, preferindo mantê-la tal qual era na infância. Assim, na crônica Recife, que faz parte de Crônicas da Província do Brasil (1957), relatando sua volta à capital pernambucana, escreverá:

Este mês que acabo de passar no Recife me repôs inteiramente no amor da minha cidade. Há dois anos atrás, quando a revi depois de uma longa ausência, desconhecia quase, tão mudada a encontrei. E sem discutir se essa mudança foi para melhor ou para pior, tive um choque, uma sensação desagradável, não sei que despeito ou magia. Queria encontrá-la como a deixei menino. Egoisticamente, queria a mesma cidade da minha infância (BANDEIRA, 2006, p. 109 - grifos nossos)

Noutra crônica ("O que era o Pernambuco de 1821"), elogiando Maria Grahan por texto escrito no Journal of a voyage to Brazil, percebemos o olhar atento do poeta-menino aos detalhes e objetos dos populares a seu redor: 
Volume 15 - Número 1 - jan/jul de 2020

\begin{abstract}
...exemplar velhinho ilustrado de estampas amoráveis desenhadas pela autora, em uma das quais tive o prazer de encontrar a preta das bananas da minha "Evocação do Recife", com todos os detalhes característicos que faziam o encanto da minha meninice nas tardes da Rua da União: o largo tabuleiro de pau, o xale vistoso de pano da costa, o colar de contas, o bracelete, a camisa muito alva caindo nos ombros magros (BANDEIRA, 2006, p. 73 - grifos nossos)
\end{abstract}

\title{
5 Considerações finais
}

Assim, a procura dessa brasilidade, portanto, perpassa toda obra poética de Bandeira, desde a valorização da cultura popular, do jeito de ser do brasileiro, até a defesa de um português do Brasil. Desde os inícios do Modernismo, Bandeira posicionou-se a favor de um "português do Brasil", uma variante do português, mas que conservou características da miscigenação, empreendida aqui pelo colonizador, defendendo que a fala do povo deveria ter lugar nos romances nacionais, como o fazia Mário de Andrade. E essa singularidade, na maneira de escrever e falar do brasileiro, foi assumida categoricamente por Manuel Bandeira, depois de impulsionada por Mário de Andrade, especialmente por meio das inúmeras crônicas que escreveu e da correspondência mantida com ele, por mais de 20 anos.

$\mathrm{Na}$ poesia de Manuel Bandeira, encontramos traços de brasilidade, como a religiosidade dessacralizada (trato informal e afetivo com os santos); valorização da oralidade e da cultura popular (a voz do povo recheada de falares e gírias), manifestando a influência cultural das três identidades que formam a brasileira (a europeia, a indígena e a africana). $\mathrm{E}$ essa mesma voz apareceria de forma implícita ou velada, mas sempre com propriedade, sem maiores censuras, em muito de sua produção em prosa também, com suas crônicas semanais no jornal A província, de Recife, e nos periódicos do Rio de Janeiro, especialmente o Jornal do Brasil, entre as décadas de 20 e 30.

Assim, contemplando a obra bandeiriana, podemos afirmar que, atento à nossa história e às manifestações culturais populares, Manuel Bandeira é, sem dúvida alguma, um dos nossos primeiros modernistas a transformar, em matéria poética, a afetividade e a cordialidade brasileira, no trato com o código linguístico, cultural e religioso europeu, impostos, entre nós, pela violência etnocêntrica da colonização.

\section{Referências}

ANDRADE, Mário de; BANDEIRA, Manuel. Cartas a Manuel Bandeira. Rio de Janeiro: Tecnoprint, 1966.

BANDEIRA, Manuel. Estrela da vida inteira. 34ª ed., Rio de Janeiro: José Olympio, 1993

BANDEIRA, Manuel. Seleta em Prosa e Verso. Liv. José Olympio Editora/INL, RJ, 1971

Saudação ao Sr. Afonso Arinos de Mello Franco. Discurso. Revista da Academia Brasileira de Letras, v. 96, p. 109 a 124, julho a dezembro, 1958.

Crônicas da província do Brasil. São Paulo: CosacNaif, 2006.

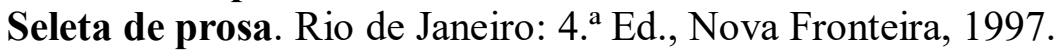

BACIU, Stefan. Manuel Bandeira de Corpo Inteiro. Rio de Janeiro: José Olympio, 1966.

CANDIDO, Antonio. Formação da Literatura Brasileiro: Momentos Decisivos. 11 $1^{\mathrm{a}}$. ed., Rio de Janeiro: Ouro sobre azul, 2007.

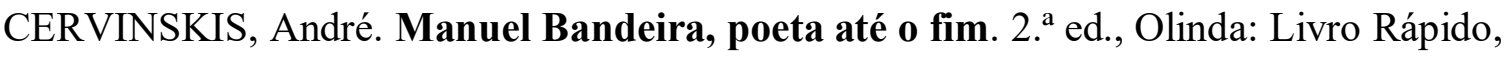
2006.

. A Identidade do Brasil em Manuel Bandeira. Olinda: Livro Rápido, 2008.

O Brasil de Manuel Bandeira. Recife. Ed. Universitária UFPE, 2010. 
Volume 15 - Número 1 - jan/jul de 2020

ESPINHARA FILHO, Ruy. Forma \& Alumbramento. 2. ' Edição, Rio de Janeiro: José Olympio: Academia Brasileira de Letras, 2004.

ORLANDI, Eni Puccinelli \& GUIMARÃES, Eduardo (Org.). Língua e Cidadania; o português no Brasil. Campinas, SP: Pontes, 1996.

ORLANDI, Eni Puccinelli (Org.). Língua e Conhecimento linguístico: para uma história das idéias no Brasil. São Paulo: Cortez, 2002.

$\mathrm{O}$ entrelugar do discurso latino-americano. In: Uma literatura nos trópicos: ensaios sobre a cultura e dependência cultural. São Paulo: Perspectiva; Secretaria de Cultura, Ciência e Tecnologia do Estado de São Paulo, 1978.

ZUMTHOR, Paul. Introdução à Poesia Oral. São Paulo: Ed. HUCITEC, 1997.

Performance, Recepção, Leitura. Trad.: Gerusa Pires Ferreira \& Sueli Fenericli.

São Paulo: Ed. HUCITEC, 2000.

Submetido em 30/04/20

Aceito em 13/08/20 